Research Article

\title{
Bone Organic-Inorganic Phase Ratio Is a Fundamental Determinant of Bone Material Quality
}

\author{
Yunhua Luo $\mathbb{D}^{1,2}$ and Ogheneriobororue Amromanoh ${ }^{1}$ \\ ${ }^{1}$ Department of Mechanical Engineering, University of Manitoba, Winnipeg, Canada \\ ${ }^{2}$ Department of Biomedical Engineering, University of Manitoba, Winnipeg, Canada \\ Correspondence should be addressed to Yunhua Luo; yunhua.luo@umanitoba.ca
}

Received 15 May 2021; Revised 2 October 2021; Accepted 21 October 2021; Published 31 October 2021

Academic Editor: Marco Parente

Copyright (C) 2021 Yunhua Luo and Ogheneriobororue Amromanoh. This is an open access article distributed under the Creative Commons Attribution License, which permits unrestricted use, distribution, and reproduction in any medium, provided the original work is properly cited.

\begin{abstract}
Background. Bone mineral density is widely used by clinicians for screening osteoporosis and assessing bone strength. However, its effectiveness has been reported unsatisfactory. In this study, it is demonstrated that bone organic-inorganic phase ratio is a fundamental determinant of bone material quality measured by stiffness, strength, and toughness. Methods and Results. Twohundred standard bone specimens were fabricated from bovine legs, with a specialized manufacturing method that was designed to reduce the effect of bone anisotropy. Bone mechanical properties of the specimens, including Young's modulus, yield stress, peak stress, and energy-to-failure, were measured by mechanical testing. Organic and inorganic mass contents of the specimens were then determined by bone ashing. Bone density and organic-inorganic phase ratio in the specimens were calculated. Statistical methods were applied to study relationships between the measured mechanical properties and the organic-inorganic phase ratios. Statistical characteristics of organic-inorganic phase ratios in the specimens with top material quality were investigated. Bone organic-inorganic phase ratio had strong Spearman correlation with bone material properties. Bone specimens that had the highest material quality had a very narrow scope of organic-inorganic phase ratio, which could be considered as the "optimal" ratio among the tested specimens. Conclusion. Bone organic-inorganic phase ratio is a fundamental determinant of bone material quality. There may exist an "optimal" ratio for the bone to achieve top material quality. Deviation from the "optimal" ratio is probably the fundamental cause of various bone diseases. This study suggests that bone organic-inorganic phase ratio should be considered in clinical assessment of fracture risk.
\end{abstract}

\section{Introduction}

Bone fracture is a common health concern among elderly people over the world, mainly due to the prevalence of osteoporosis and accident fall in the population [1-4]. Bone strength is a key mechanical property for the assessment of fracture risk. A direct and reliable way for the determination of bone strength is by mechanical testing, which is however invasive and not applicable to the human body. Bone density (BD) has been established as an indirect way to estimate bone strength. Extensive experimental studies have shown that at the material level, there is a relationship between bone strength and $\mathrm{BD}$ [5-8], and $\mathrm{BD}$ can be noninvasively measured by imaging technologies such as dual energy $\mathrm{X}$ ray absorptiometry and quantitative computed tomography
[9-11]. Bone mineral density is recommended by the World Health Organization as a gold reference for the screening of osteoporosis and for the assessment of fracture risk $[12,13]$. It is important to note that bone mineral density refers to the content of inorganic minerals in a unit bone volume, while $\mathrm{BD}$ includes all the material compositions.

Numerous clinical studies have shown that bone mineral density is not a reliable predictor of fracture risk [14-19]. Bone fractures often occur in people who are not in high risk if assessed by bone mineral density. With a close examination of a variety of methods developed for the prediction of fracture risk, de Bakker et al. [20] pointed out the importance of bone material properties in determining wholebone mechanics. Based on a critical analysis of the biomechanical variables involved in clinical assessment of hip 


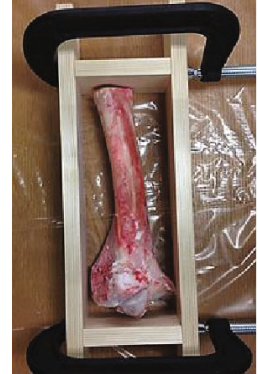

(a)

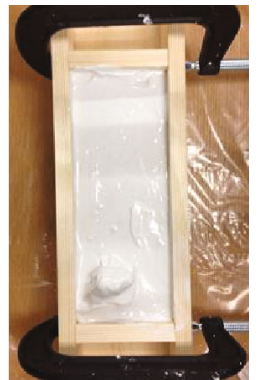

(b)

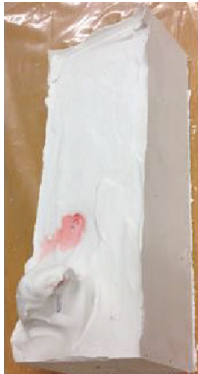

(c)

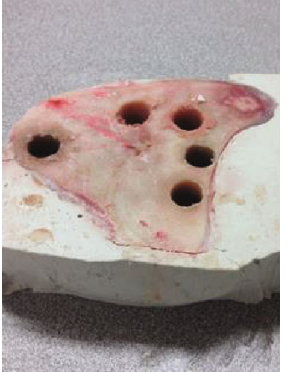

(d)

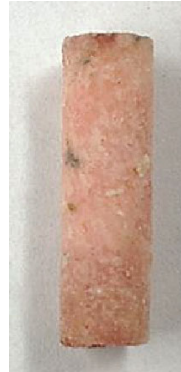

(e)

Figure 1: (a) Soft tissues were completely removed, and the bone was positioned in mold. (b) Mixed plaster of Paris was poured in. (c) After plaster consolidation, mold was removed. (d) The molded femur was transversely sliced in $30 \mathrm{~mm}$ thickness using a laser-guided mitre saw; bone specimens were cored from the slices using diamond coring bit of $8 \mathrm{~mm}$ diameter. (e) Information of each specimen, including animal, femur, anatomic site, and bone type, was recorded; the specimens were then labeled, wrapped with kitchen film, put in air-tight plastic container, and then stored in the freezer $\left(-20^{\circ}\right)$ before testing.

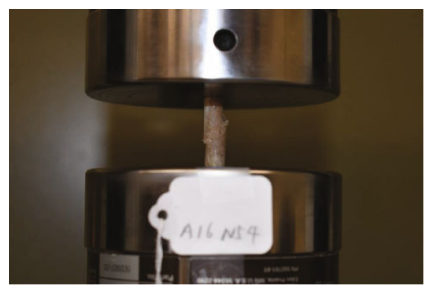

(a)

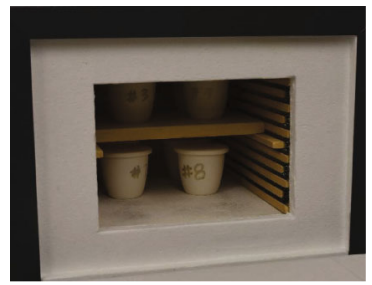

(b)

Figure 2: (a) Compression testing. (b) Bone ashing.

fracture risk, it was identified that the oversimplified relationship between bone strength and bone material compositions probably has substantial adverse effect on the accuracy of the biomechanical models [21]. Bone compositions play different roles in regulation of bone strength and other mechanical properties [22, 23]. The inorganic minerals mainly regulate bone stiffness and compressive strength, while the organic proteins primarily govern bone flexibility and toughness [24-26]. The existing bone elasticity-density relations have a sole density variable, which is not able to describe the composition difference in bones, and thus have numerous fundamental limitations. For example, the relations are found anatomic site-dependent [27]; they can not explain why old bones are more brittle than young bones even they have similar density [28], and why bones have different compressive and tensile strength $[29,30]$.

Our previous study has shown that bone material quality is dependent on the quality and quantity of organic and inorganic phases [31]. In this paper, it is further demonstrated that bone organic-inorganic phase ratio is a fundamental determinant of bone material quality measured by stiffness, strength, and toughness.

\section{Materials and Methods}

2.1. Consideration of Bone as an Organic-Inorganic Composite Material. Bone has complicated chemical and material compositions at the microscopic scale [32]. At the material level, bone is composed of inorganic minerals, organic proteins, and water [24]. About $90 \%$ of the minerals are hydroxyapatite, and $90 \%$ of the proteins are type I colla-
TABLE 1: Spearman correlation ( $p$ value) between organic-inorganic phase ratio and bone material properties.

\begin{tabular}{lc}
\hline Material property & Spearman correlation $\rho(p$ value $)$ \\
\hline Density & $-0.89(p<0.001)$ \\
Young's modulus & $-0.83(p<0.001)$ \\
Yield stress & $-0.89(p<0.001)$ \\
Peak stress & $-0.92(p<0.001)$ \\
Energy-to-failure & $-0.85(p<0.001)$ \\
\hline
\end{tabular}

gen protein $[33,34]$. The proteins and water are combined in one phase but still collectively call them "organic" phase. Water exists in two forms in bone, i.e., water bonded with proteins and free water in pores [35]. It is difficult to separate bounded and free water in bone; the concern is that excessive removal of bounded water can degrade proteins and thus substantially change their mechanical properties $[35,36]$. By considering bone as an organic-inorganic composite material, the organic and inorganic content can be determined by ashing. Organic matters including water are burned out during ashing, while inorganic minerals remain.

2.2. Bone Specimens. Forty bovine leg bones (10 healthy cows, age of 12 to 18 months) were acquired from local certified slaughterhouses. The harvested bones were immediately wrapped in air-tight plastic bags and stored in a freezer with the temperature set at $-20^{\circ} \mathrm{C}$. A specially designed method as described in Figure 1 was used to fabricate bone specimens. The bone specimens manufactured with this method are approximately along the femur axis, 

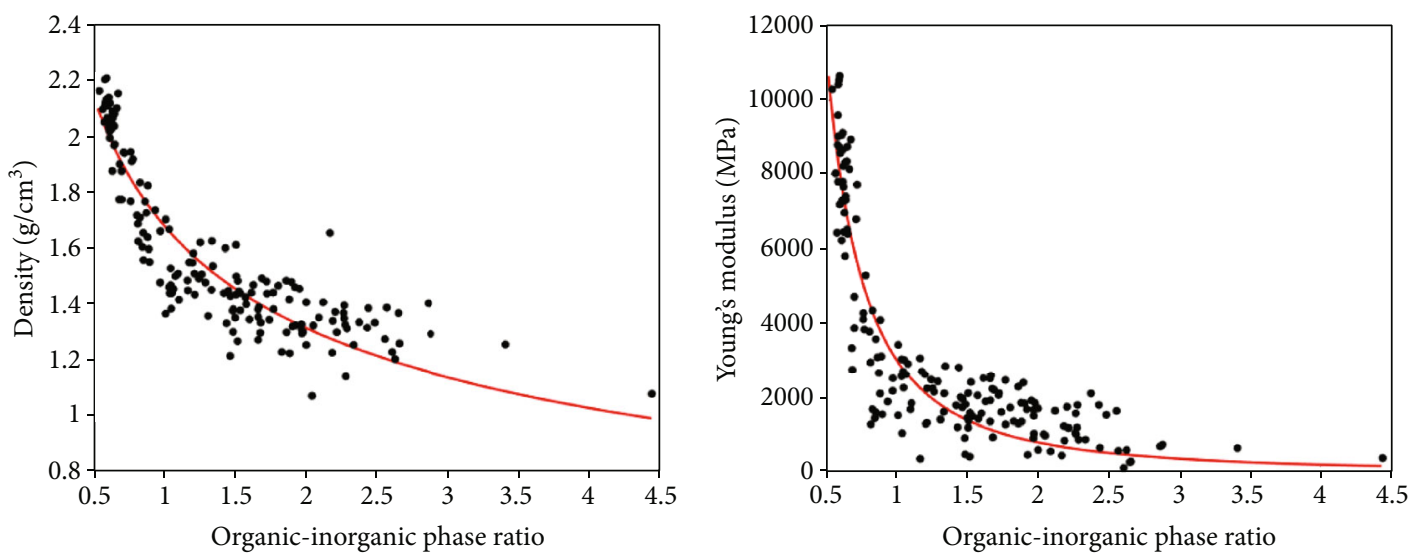

$y=1.6973 \cdot x^{-0.35}, R^{2}=0.85$

- Experimental data

— $y=3028 \cdot x^{-1.91}, R^{2}=0.85$

- Experimental data

(a)

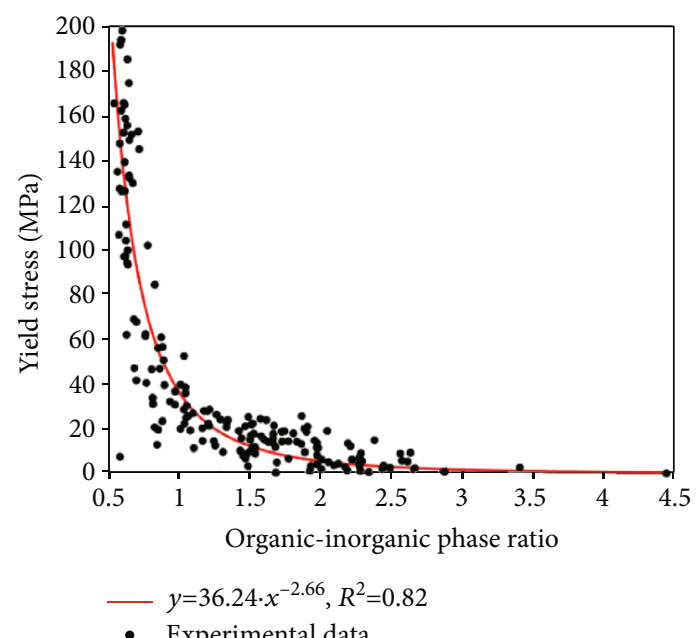

(c) (b)

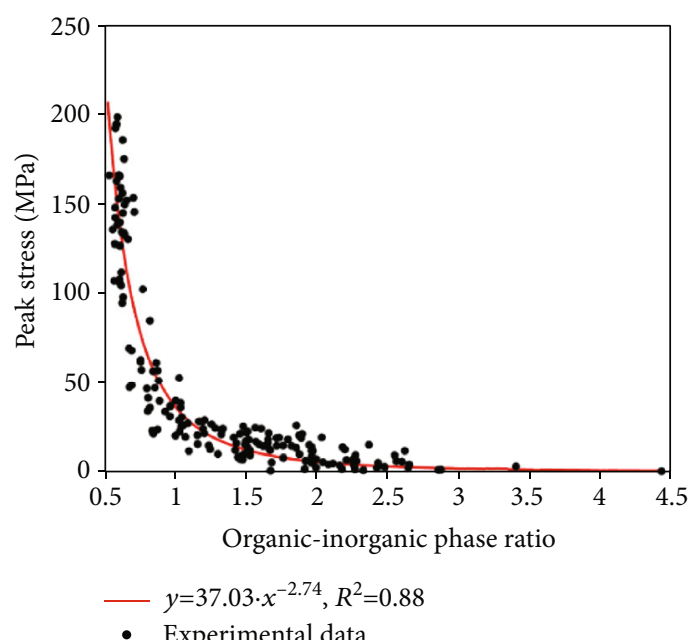

(d)

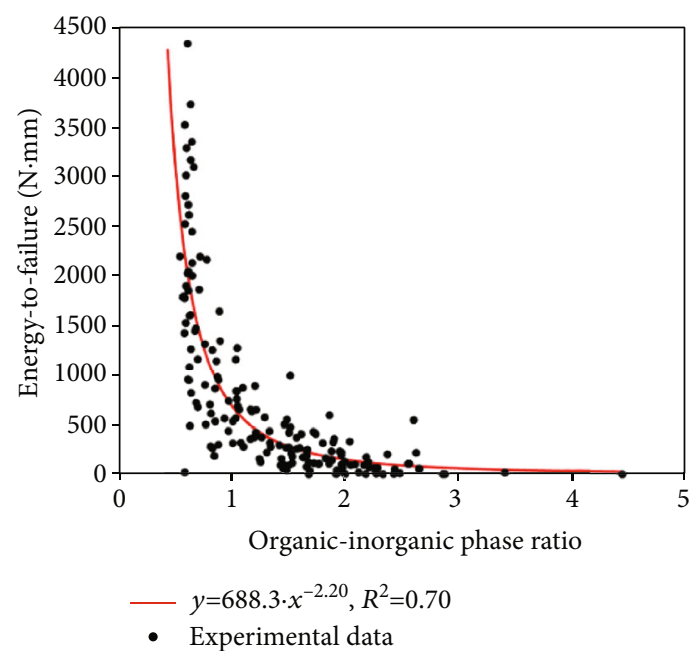

(e)

FIGURE 3: Variations of bone material properties with organic-inorganic phase ratio: (a) density; (b) Young's modulus; (c) yield stress; (d) peak stress; (e) energy-to-failure. 
TABle 2: Statistical characteristics of organic-inorganic phase ratio in groups of specimens having top material quality.

\begin{tabular}{llllllr}
\hline \multirow{2}{*}{ Material property } & \multicolumn{2}{c}{ Top 10\% } & \multicolumn{2}{c}{ Top 20\% } & \multicolumn{2}{c}{ Top 30\% } \\
& Mean (SD) & Range & Mean (SD) & Range & Mean (SD) & Range \\
\hline Density & $0.61(0.03)$ & $(0.54,0.68)$ & $0.62(0.04)$ & $(0.54,0.77)$ & $0.64(0.06)$ & $(0.54,0.83)$ \\
Young's modulus & $0.61(0.01)$ & $(0.54,0.68)$ & $0.62(0.04)$ & $(0.54,0.72)$ & $0.65(0.07)$ & $(0.54,0.88)$ \\
Yield stress & $0.62(0.02)$ & $(0.54,0.71)$ & $0.63(0.05)$ & $(0.54,0.78)$ & $0.65(0.07)$ & $(0.54,0.88)$ \\
Peak stress & $0.62(0.04)$ & $(0.54,0.71)$ & $0.62(0.04)$ & $(0.54,0.72)$ & $0.64(0.06)$ & $(0.54,0.83)$ \\
Energy-to-failure & $0.62(0.05)$ & $(0.54,0.72)$ & $0.63(0.07)$ & $(0.54,0.79)$ & $0.65(0.12)$ & $(0.54,0.89)$ \\
\hline
\end{tabular}

and the effect of bone anisotropy on mechanical properties is thus reduced. Two-hundred cylindrical specimens were manufactured. Experimental data were successfully measured from 173 specimens (length $28.5 \pm 2.2 \mathrm{~mm}$, diameter $7.8 \pm 0.4 \mathrm{~mm}$ ), including 95 cortical and 78 cancellous bones.

2.3. Mechanical Testing and Bone Ashing. Prior to mechanical testing, specimens were taken out from the freezer and dwelled in room temperature and humidity for four hours, so that bone temperature and moisture did not change anymore. The procedure that was applied to generate experimental data in this study is described as follows. Specimen length, diameter, and weight were measured using caliper and digital weight scale. Specimens were compressed until failure using an MTS Insight Electromechanical Testing System, see Figure 2(a), with a loading rate of $1.5 \mathrm{~mm} /$ minute. The testing system was periodically calibrated by a certified technician. Bone mechanical properties, including Young's modulus, yield stress, peak stress, and energy-to-failure, were automatically measured by the testing system. After mechanical testing, specimens were ashed in a muffle furnace (Fisher Scientific, Canada) under $700^{\circ} \mathrm{C}$ for 20 hours, compare Figure 2(b). Each specimen was ashed in a separate crucible with cover. The weight lost during the ashing was taken as the organic mass; the ash weight was measured and taken as the inorganic mass.

2.4. Statistical Analyses. To study the effect of organicinorganic phase ratio on bone material properties, Spearman correlation and $p$ value were calculated; nonlinear model fitting was conducted. A number of nonlinear models, including polynomials of different orders and exponential functions, were attempted to find out the best fitting.

To investigate statistical characteristics of organicinorganic phase ratio in specimens of high material quality, specimen groups that had the top $10 \%, 20 \%$, and $30 \%$ of density, Young's modulus, yield stress, peak stress, and energy-to-failure were identified; mean values and standard deviations of the ratios in the groups were calculated.

\section{Results}

Spearman correlation $(\rho)$ and $p$ value that show the correlations of BD, Young's modulus, yield stress, compressive strength, and energy-to-failure with organic-inorganic phase ratio are listed in Table 1.
Relationships between bone material properties and organic-inorganic phase ratio were found highly nonlinear. The models that had the best fitting with the experimental data were in the form of exponential function

$$
y=a \cdot r^{b}
$$

where $r$ is the organic-inorganic phase ratio, $y$ is one of the material properties shown in Table 1 , and $a$ and $b$ are coefficients determined by nonlinear model fitting. The coefficients of determination $\left(R^{2}\right)$ were 0.85 for density, 0.85 for Young's modulus, 0.82 for yield stress, 0.88 for peak stress, and 0.70 for energy-to-failure. The nonlinear models together with the experimental data are shown in Figure 3.

Statistical characteristics of organic-inorganic phase ratios in the specimen groups of top $10 \%, 20 \%$, and $30 \%$ of density, Young's modulus, yield stress, peak stress, and energy-to-failure are listed in Table 2.

The results show that bone organic-inorganic phase ratio had significant effect on the material properties (Table 1), and the effect was nonlinear (Figure 3), suggesting that a small deviation of the ratio from the means in Table 2 may substantially reduce bone material quality.

\section{Discussion}

Spearman correlations and $p$ values in Table 1 show that bone organic-inorganic phase ratio has strong $(\rho=-0.83-$ -0.92) and significant $(p<0.001)$ correlations with bone material properties, suggesting that bone organic-inorganic phase ratio is an important determinant of bone material quality. By integrating the above finding with those from previous studies [8], one can produce a more complete picture (see Figure 4) regarding the dependence of bone material quality on bone composition. Several studies, which have been comprehensively reviewed by Helgason et al. [8], have evaluated the relationship between bone stiffness/strength and $\mathrm{BD}$. This study further revealed that $\mathrm{BD}$ is dependent on organic-inorganic phase ratio, see Table 1 and Figure 3(a). Therefore, bone organic-inorganic phase ratio is a more fundamental determinant than $\mathrm{BD}$ in regulation of bone material quality. Correlations in Table 1 also show that, with the increasing of organic content, bone stiffness and strength would decrease, which is consistent with the mechanics of composite materials [37]. If the bone is considered as a two-phase composite, bone organic phase plays the role of the matrix, while the inorganic phase acts as the reinforcement or inclusion. The organic phase of bone, which 


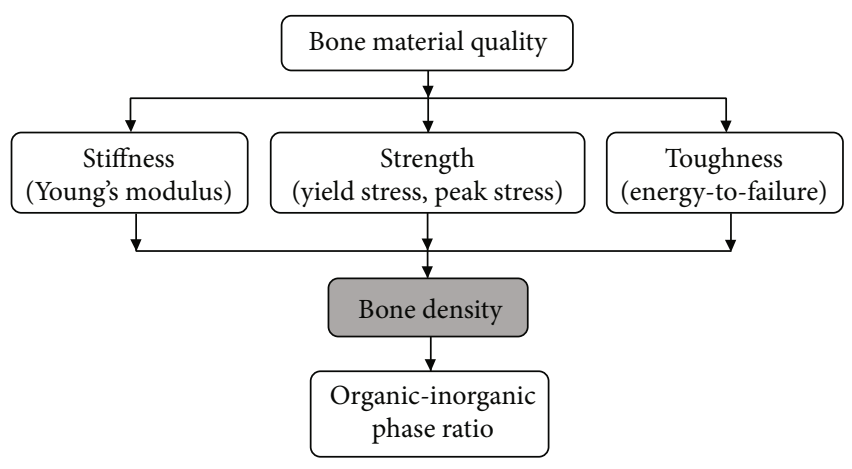

FIgURE 4: The dependence of bone material quality on organicinorganic phase ratio.

mainly consists of type I collagen proteins, has much lower density, stiffness, and strength than the inorganic phase that is dominated by hydroxyapatite $[38,39]$. Based on the mechanics of composite materials, a higher organic content would definitely result in lower stiffness and strength [37].

Results in Figure 3 and Table 2 further suggest that there exists a certain organic-inorganic phase ratio for bone to achieve top material quality. It is interesting to note that, if testing error is considered, the top material properties of the tested specimens were achieved by almost the same organic-inorganic phase ratio (see Table 2). For example, the ratio was between 0.61 and 0.62 for top $10 \%$ material properties, which can be considered as the optimal ratio in the tested specimens. The existence of optimal phase ratio is probably the result of balancing between the different roles of organic and inorganic phases in the regulation of bone material properties. First, collagen protein in extracellular matrix is the "house" for the accommodation of inorganic minerals, and a unit volume of collagen protein can only accommodate a certain amount of inorganic minerals [40]. Therefore, the quantity and quality of collagen protein determine the quantity of inorganic minerals that can be deposited in a bone. Either inadequate or excessive amount of collagen protein would result in a weak bone. Second, bone toughness is a more crucial property than bone strength to resist fracture [41] but has not been considered in the clinical assessment of fracture risk. In material science, toughness is the ability of a material to absorb mechanical energy and sustain deformation without fracturing. Material toughness is measured by the area under the stress-strain curve. In order to be tough, a material must be both strong and ductile, which are, respectively, governed by the bone inorganic and organic phases.

One limitation of this study is that only young and healthy bones were tested, due to the difficulty in the acquisition of diseased bovine bones. However, on the basis of composite material theory, it can be inferred that a higher organic-inorganic phase would improve bone ductility but compromise strength. On the other hand, a lower ratio would increase bone strength but also promote fragility. Emerging research evidence shows that imbalance between organic and inorganic phase is a fundamental cause of various bone diseases [24]. For example, osteomalacia, also referred as softened bone disease, is characterized by a low mineralization of bone matrix [42-44], or equivalently, the organic-inorganic phase ratio is abnormally high. In contrast, osteogenesis imperfecta, or brittle bone disease, is attributed to the deficiency of producing collagen protein in the body [45-47]; the bone thus has an abnormally low organic-inorganic phase ratio. Osteoporosis is a bone disease closely related to aging. With aging, the body has a reduced ability to produce new collagen proteins in remodeling [48-50], resulting in organic-inorganic phase ratio shifted to the lower side.

The findings from this study indicate that, to improve the clinical assessment of bone strength and fracture risk, it is necessary to measure bone protein content in addition to bone mineral density, which requires a noninvasive technique such as bone imaging. Existing bone imaging modalities such as magnetic resonance imaging and quantitative computed tomography can only measure either the organic or the inorganic content [11] but not both. Recent advances in water- and fat-suppressed projection imaging [51, 52] make it possible to noninvasively detect both organic and inorganic content, thus providing a feasible way for the implementation of the findings to clinical applications.

\section{Conclusions}

Based on the results in this study, it can be concluded that bone organic-inorganic phase ratio is a fundamental determinant of bone material quality, and there exists an "optimal" ratio for the bone to achieve top material quality. Deviation from the "optimal" ratio is probably the fundamental cause of various bone diseases. This study suggests that bone organic-inorganic phase ratio should be considered as a risk factor in clinical assessment of fracture risk.

\section{Data Availability}

The experimental datasets produced by the current study are available from the corresponding author on reasonable request.

\section{Ethical Approval}

Ethical approval is not applicable.

\section{Consent}

No consent was necessary

\section{Conflicts of Interest}

The authors declare that they have no competing interests.

\section{Authors' Contributions}

Dr. Y. Luo designed the research and experiment procedure, analyzed the experimental data, and wrote the manuscript. Mr. O. Amromanoh (Master student) did bone testing and collected all the experimental data. 


\section{Acknowledgments}

The reported research has been supported by the Natural Sciences and Engineering Research Council of Canada (NSERC) via grant RGPIN-2019-05372. NSERC is a government funding agency of Canada.

\section{References}

[1] P. Kannus, J. Parkkari, H. Sievänen, A. Heinonen, I. Vuori, and M. Järvinen, "Epidemiology of hip fractures," Bone, vol. 18, no. 1, pp. S57-S63, 1996.

[2] G. F. Fuller, "Falls in the elderly," American Family Physician, vol. 61, 2000.

[3] K. O. Berg, S. L. Wood-Dauphinee, J. I. Williams, and B. Maki, "Measuring balance in the elderly: validation of an instrument," Canadian Journal of Public Health, vol. 83, Supplement 2, pp. S7-11, 1992.

[4] J. A. Kanis, A. Oden, E. V. McCloskey, H. Johansson, D. A. Wahl, and C. Cooper, "A systematic review of hip fracture incidence and probability of fracture worldwide," Osteoporosis international, vol. 23, no. 9, pp. 2239-2256, 2012.

[5] I. Fleps, H. Bahaloo, P. K. Zysset, S. J. Ferguson, H. Pálsson, and B. Helgason, "Empirical relationships between bone density and ultimate strength: a literature review," Journal of the Mechanical Behavior of Biomedical Materials, vol. 110, p. 103866, 2020.

[6] T. M. Keaveny, E. F. Morgan, G. L. Niebur, and O. C. Yeh, "Biomechanics of trabecular bone," Annual review of biomedical engineering, vol. 3, no. 1, pp. 307-333, 2001.

[7] E. F. Morgan, G. U. Unnikrisnan, and A. I. Hussein, "Bone mechanical properties in healthy and diseased states," Annual review of biomedical engineering, vol. 20, no. 1, pp. 119-143, 2018.

[8] B. Helgason, E. Perilli, E. Schileo, F. Taddei, S. Brynjólfsson, and M. Viceconti, "Mathematical relationships between bone density and mechanical properties: a literature review," Clinical biomechanics, vol. 23, no. 2, pp. 135-146, 2008.

[9] G. Guglielmi, "Quantitative computed tomography (QCT) and dual X-ray absorptiometry (DXA) in the diagnosis of osteoporosis," European Journal of Radiology, vol. 20, no. 3, pp. 185-187, 1995.

[10] G. M. Blake and I. Fogelman, "The role of DXA bone density scans in the diagnosis and treatment of osteoporosis," Postgraduate Medical Journal, vol. 83, no. 982, pp. 509-517, 2007.

[11] J. S. Bauer and T. M. Link, "Advances in osteoporosis imaging," European Journal of Radiology, vol. 71, no. 3, pp. 440449, 2009.

[12] J. M. Kling, B. L. Clarke, and N. P. Sandhu, "Osteoporosis prevention, screening, and treatment: a review," Journal of women's health, vol. 23, no. 7, pp. 563-572, 2014.

[13] A. Unnanuntana, B. P. Gladnick, E. Donnelly, and J. M. Lane, "The assessment of fracture risk," The Journal of Bone and Joint Surgery American Volume, vol. 92, no. 3, pp. 743-753, 2010.

[14] T. J. Wilkin, "For and against: bone densitometry is not a good predictor of hip fracture For Against," BMJ, vol. 323, no. 7316, pp. 795-799, 2001.

[15] B. R. McCreadie and S. A. Goldstein, "Biomechanics of fracture: is bone mineral density sufficient to Assess risk?," Journal of Bone and Mineral Research, vol. 15, no. 12, pp. 2305-2308, 2000.

[16] R. E. Small, "Uses and limitations of bone mineral density measurements in the management of osteoporosis," MedGenMed, vol. 7, 2005.

[17] K. H. Rubin, T. Friis-Holmberg, A. P. Hermann, B. Abrahamsen, and K. Brixen, "Risk assessment tools to identify women with increased risk of osteoporotic fracture: complexity or simplicity? A systematic review," Journal of Bone and Mineral Research, vol. 28, no. 8, pp. 1701-1717, 2013.

[18] N. B. Watts, C. Cooper, R. Lindsay et al., "Relationship between changes in bone mineral density and vertebral fracture risk associated with risedronate: greater increases in bone mineral density do not relate to greater decreases in fracture risk," Journal of Clinical Densitometry, vol. 7, no. 3, pp. 255261, 2004.

[19] C. A. Cefalu, "Is bone mineral density predictive of fracture risk reduction?," Current medical research and opinion, vol. 20, no. 3, pp. 341-349, 2004.

[20] C. M. J. de Bakker, W.-J. Tseng, Y. Li, H. Zhao, and X. S. Liu, "Clinical evaluation of bone strength and fracture risk," Current osteoporosis reports, vol. 15, no. 1, pp. 32-42, 2017.

[21] Y. Luo, "On challenges in clinical assessment of hip fracture risk using image-based biomechanical modelling: a critical review," Journal of Bone and Mineral Metabolism, vol. 39, no. 4, pp. 523-533, 2021.

[22] O. A. Tertuliano and J. R. Greer, "The nanocomposite nature of bone drives its strength and damage resistance," Nature Materials, vol. 15, 2016.

[23] A. L. Boskey and R. Coleman, "Aging and bone," Journal of Dental Research, vol. 89, no. 12, pp. 1333-1348, 2010.

[24] A. L. Boskey, "Bone composition: relationship to bone fragility and antiosteoporotic drug effects," BoneKey Reports, vol. 2, 2013.

[25] P. Fratzl and R. Weinkamer, "Nature's hierarchical materials," Progress in Materials Science, vol. 52, no. 8, pp. 1263-1334, 2007.

[26] N. H. Hart, S. Nimphius, T. Rantalainen, A. Ireland, A. Siafarikas, and R. U. Newton, "Mechanical basis of bone strength: influence of bone material, bone structure and muscle action," Journal of musculoskeletal \& neuronal interactions, vol. 17, 2017.

[27] E. F. Morgan, H. H. Bayraktar, and T. M. Keaveny, "Trabecular bone modulus-density relationships depend on anatomic site," Journal of Biomechanics, vol. 36, no. 7, pp. 897-904, 2003.

[28] I. Malkin, G. Bigman, R. Matias et al., "Age-related changes of bone strength phenotypes: observational follow-up study of hand bone mineral density," Archives of Osteoporosis, vol. 1, no. 1-2, pp. 59-68, 2006.

[29] T. M. Keaveny, E. F. Wachtel, C. M. Ford, and W. C. Hayes, "Differences between the tensile and compressive strengths of bovine tibial trabecular bone depend on modulus," Journal of Biomechanics, vol. 27, no. 9, pp. 1137-1146, 1994.

[30] D. L. Kopperdahl and T. M. Keaveny, "Yield strain behavior of trabecular bone," Journal of Biomechanics, vol. 31, no. 7, pp. 601-608, 1998.

[31] Y. Luo and X. Wu, "Bone quality is dependent on the quantity and quality of organic-inorganic phases," Journal of Medical and Biological Engineering, vol. 40, no. 2, pp. 273-281, 2020.

[32] A. L. Boskey and S. Doty, "Mineralized Tissue: Histology, Biology and Biochemistry," in Osteogenesis Imperfecta: A 
Translational Approach to Brittle Bone Disease, J. Shapiro, F. Glorieux, P. Byers, and P. Sponsellor, Eds., Elsevier, New York, 2013.

[33] L. E. Craig, K. E. Dittmer, and K. G. Thompson, Bones and Joints, chapter 2, Saunders Ltd, 6 edition, 2016.

[34] A. L. Boskey and P. G. Robey, The Regulatory Role of Matrix Proteins in Mineralization of Bone, chapter 11, Academic Press, 4 edition, 2013.

[35] M. Granke, M. D. Does, and J. S. Nyman, "The role of water compartments in the material properties of cortical bone," Calcified tissue international, vol. 97, no. 3, pp. 292-307, 2015.

[36] E. E. Wilson, A. Awonusi, M. D. Morris, D. H. Kohn, M. M. J. Tecklenburg, and L. W. Beck, "Three structural roles for water in bone observed by solid-state NMR," Biophysical journal, vol. 90, no. 10, pp. 3722-3731, 2006.

[37] R. M. Christensen, "A critical evaluation for a class of micromechanics models," Journal of the Mechanics and Physics of Solids, vol. 38, no. 3, pp. 379-404, 1990.

[38] W. Y. Ching, P. Rulis, and A. Misra, "Ab initio elastic properties and tensile strength of crystalline hydroxyapatite," Acta Biomaterialia, vol. 5, no. 8, pp. 3067-3075, 2009.

[39] Z. L. Shen, M. R. Dodge, H. Kahn, R. Ballarini, and S. J. Eppell, "Stress-strain experiments on individual collagen fibrils," Biophysical Journal, vol. 95, no. 8, pp. 3956-3963, 2008.

[40] H. P. Wiesmann, U. Meyer, U. Plate, and H. J. Höhling, "Aspects of collagen mineralization in hard tissue formation," International review of cytology, vol. 242, 2004.

[41] C. J. Hernandez and M. C. H. van der Meulen, "Understanding bone strength is not enough," Journal of Bone and Mineral Research, vol. 32, no. 6, pp. 1157-1162, 2017.

[42] P. Roschger, H. S. Gupta, A. Berzlanovich et al., "Constant mineralization density distribution in cancellous human bone," Bone, vol. 32, no. 3, pp. 316-323, 2003.

[43] D. Faibish, A. Gomes, G. Boivin, I. Binderman, and A. Boskey, "Infrared imaging of calcified tissue in bone biopsies from adults with osteomalacia," Bone, vol. 36, no. 1, pp. 6-12, 2005.

[44] M. Saghafi, A. Azarian, K. Hashemzadeh, M. Sahebari, and Z. Rezaieyazdi, "Bone densitometry in patients with osteomalacia: is it valuable?," Clinical Cases in Mineral and Bone Metabolism, vol. 10, 2013.

[45] N. Bishop, "Bone material properties in osteogenesis imperfecta," Journal of Bone and Mineral Research, vol. 31, no. 4, pp. 699-708, 2016.

[46] A. Carriero, E. A. Zimmermann, A. Paluszny et al., "How tough is brittle bone? Investigating osteogenesis imperfecta in mouse bone," Journal of Bone and Mineral Research, vol. 29, no. 6, pp. 1392-1401, 2014.

[47] A. Forlino, W. A. Cabral, A. M. Barnes, and J. C. Marini, "New perspectives on osteogenesis imperfecta," Nature Reviews Endocrinology, vol. 7, no. 9, pp. 540-557, 2011.

[48] G. E. Sroga and D. Vashishth, "Effects of bone matrix proteins on fracture and fragility in osteoporosis," Current osteoporosis reports, vol. 10, no. 2, pp. 141-150, 2012.

[49] M. F. Young, "Bone matrix proteins: their function, regulation, and relationship to osteoporosis," Osteoporosis international, vol. 14, no. S3, pp. 35-42, 2003.

[50] O. Demontiero, C. Vidal, and G. Duque, "Aging and bone loss: new insights for the clinician," Therapeutic advances in musculoskeletal disease, vol. 4, no. 2, pp. 61-76, 2012.

[51] C. Huang, J. Ouyang, T. G. Reese, Y. Wu, G. El Fakhri, and J. L. Ackerman, "Continuous MR bone density measurement using water- and fat-suppressed projection imaging (WASPI) for PET attenuation correction in PET-MR," Physics in Medicine \& Biology, vol. 60, no. 20, pp. N369-N381, 2015.

[52] Y. Wu, M. I. Hrovat, J. L. Ackerman et al., "Bone matrix imaged in vivo by water- and fat-suppressed proton projection MRI (WASPI) of animal and human subjects," Journal of Magnetic Resonance Imaging, vol. 31, no. 4, pp. 954-963, 2010. 